\title{
Влияние частичной обструкции общего желчного протока без гипербилирубинемии на печень
}

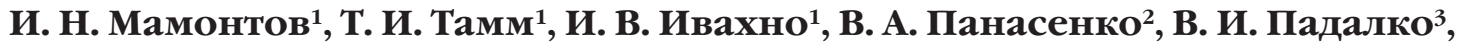 \\ И. И. Зульфугаров ${ }^{1}$ \\ ${ }^{1}$ Харьковская медицинская академия последипломного образования, \\ ${ }^{2}$ Харьковский национальный медицинский университет, \\ ${ }^{3}$ Харьковский национальный университет имени В. Н. Каразина

\section{The impact of partial obstruction of common biliary duct without hyperbilirubinemia on the liver}

\author{
I. N. Mamontov ${ }^{1}$, T. I. Tamm ${ }^{1}$, I. V. Ivakhno ${ }^{1}$, V. A. Panasenko ${ }^{2}$, V. I. Padalko ${ }^{3}$, I. I. Zulfugarov ${ }^{1}$ \\ ${ }^{1}$ Kharkov Medical Academy of Postgraduate Education, \\ ${ }^{2}$ Kharkov National Medical University, \\ ${ }^{3}$ Karazin Kharkov National University
}

\section{Реферат}

Цель. Изучение в эксперименте морфологических изменений печени и биохимических показателей крови при частичной обструкции общего желчного протока (ЧООЖП) без гипербилирубинемии.

Материалы и методы. На 34 крысах моделировали ЧООЖП. Животных выводили из эксперимента на 3, 7, 14, 21, 28-е и 35-е сутки. Определяли содержание билирубина, альбумина, мочевины сыворотки крови и активность аланинаминотрансферазы (АЛТ), аспартатаминотрансферазы (АСТ), щелочной фосфатазы (ЩФ). Измеряли диаметр общего желчного протока, массу и объем печени, исследовали ее гистологию, выполняли морфометрию. Контролем служили 17 животных.

Результаты. У 14 (41,2\%) животных наблюдали ЧООЖП без гипербилирубинемии. Максимальные морфологические изменения отмечены на 28 - 35-е сутки: увеличение массы печени на $31 \%$ и ее объема на 25,5\%; увеличение числа и дилатация желчных протоков, увеличение числа синусоидальных клеток, площади гепатоцитов, наличие фиброза II степени в 4 из 5 наблюдений. Изменения биохимических показателей были достоверными только на 3 - 7-е сутки: содержание альбумина снизилось до $(21,6 \pm 2,5)$ г/л, контрольный показатель - $(26,7 \pm 1,6)$ г/л. В течение эксперимента активность АЛТ, АСТ, ЩФ, содержание мочевины не отличались от контрольных величин.

Выводы. Несмотря на полную функциональную компенсацию, ЧООЖП без гипербилирубинемии приводит к значимым морфологическим изменениям печени.

ключевые слова: частичная обструкция общего желчного протока; холестаз; морфология печени; гипербилирубинемия.

Abstract

Objective. Experimental studying of hepatic morphological changes and the blood biochemical indices in partial obstruction of common biliary duct (POCBD) without hyperbilirubinemia.

Materials and methods. POCBD was simulated on 34 laboratory animals. The animals were excluded from the experiment on the 3,7,14,21,28-th and 35-th day. The content of bilirubin, albumin, the blood serum urea and activity of alanine aminotransferase (AlAT), aspartate aminotransferase (AsAT), alkaline phosphatase (APH) were measured. The common biliary duct diameter, hepatic volume and mass were measured, hepatic histology investigated, and morphometry was performed. Control group consisted of 17 experimental animals.

Results. In 14 (41.2\%) experimental animals POCBD without hyperbilirubinemia was observed. Maximal morphological changes were noted on the $28-35^{\text {th }}$ day: the hepatic mass enhancement by $31 \%$ and the hepatic volume - by $25.5 \%$; increase of the number and dilatation of biliary ducts, increase of the sinusoidal cells quantity, of the hepatocytes square, presence of the Degree II in 4of 5 observations. The changes of biochemical indices were trustworthy on the $3-7$-th day: the albumin content have lowered down to $(21.6 \pm 2.5) \mathrm{g} / \mathrm{l}$, while a control index constitutes $(26.7 \pm 1.6) \mathrm{g} / \mathrm{l}$. Activity of AlAT, AsAT, APH, the urea content during the experiment did not differ from the control values.

Conclusion. Despite a complete functional compensation, POCBD without hyperbilirubinemia leads to significant morphological changes in the live, in spite of complete functional compensation presence.

Keywords: partial obstruction of common biliary duct; cholestasis; morphology of the liver; hyperbilirubinemia. 
Обструкция внепеченочных желчных путей - клиническое состояние, часто обусловленное осложненной желчнокаменной болезнью, злокачественными новообразованиями периампулярной зоны, реже - другими заболеваниями, в частности хроническим панкреатитом $[1,2]$. Наиболее типичным проявлением обструктивного холестаза является гипербилирубинемия - синдром желтухи, который, тем не менее, констатируют не у всех больных $[2,3]$. Это в свою очередь может затруднять диагностику и влиять на выбор дальнейшей тактики, направленной на выявление причины обструкции и ее устранение [3]. Как обструкция внепеченочных желчных путей, протекающая без синдрома желтухи, влияет на морфологию и функциональное состояние печени, в клинической практике не изучено. На экспериментальных моделях холестаза в основном изучены последствия полной обструкции [4 6]. Исследования частичной обструкции внепеченочных желчных путей немногочисленны $[4,5,7,8]$.

Цель исследования: изучение в эксперименте морфологических изменений печени и биохимических показателей крови при частичной обструкции внепеченочных желчных путей, не сопровождающейся гипербилирубинемией.

\section{Материалы и методы исследования}

В эксперименте использованы 34 крысы-самцы массой тела 270 - 310 г, которых удерживали в стандартных лабораторных условиях. Оперативные вмешательства выполняли с соблюдением правил антисептики под общим обезболиванием. Частичную обструкцию общего желчного протока (ЧООЖП) воспроизводили согласно модели, предложенной G. Sekas [9]: общий желчный проток (ОЖП) перевязывали вместе с инструментом заданного диаметра. В качестве инструмента использовали стандартные медицинские иглы с наружным диаметром 0,7 - 1,1 мм. После затягивания лигатуры (капрон 4/0) иглу извлекали. Таким образом диаметр лигатурного кольца был ограничен диаметром иглы. Контролем служили 17 животных.

Животных выводили из эксперимента на 3, 7, 14, 21 , 28-е и 35-е сутки. Оценивали состояние органов брюшной полости. Критерием ЧООжП было расширение протока выше лигатуры с наличием желчи в просвете двенадцатиперстной кишки. Стандартным методом определяли содержание билирубина, альбумина, мочевины сыворотки крови, а также активность АЛТ, АСТ и ЩФ. Измеряли диаметр ОЖП выше лигатуры, производили забор пе- чени. Измеряли массу печени (МП). Объем печени (ОП) определяли по объему вытесняемой воды при ее погружении в лабораторную колбу с градуированной шкалой объема. Печень фиксировали в 10\% растворе формалина. Гистологические препараты, изготовленные по стандартной методике, окрашивали гематоксилином и эозином и по методу Ван-Гизона. Оценивали степень фиброза [10]. Выполняли морфометрический анализ. Программой для морфометрических исследований служила ImageJ.

Изучали следующие микроморфометрические показатели: площадь гепатоцитов (ПГ), ядерно-цитоплазматическое отношение (ЯЦО) гепатоцитов - отношение площади их ядер к площади цитоплазмы, объемную плотность гепатоцитов (ОПГ) - отношение объема гепатоцитов к общему объему тканей печени, объемную плотность портальных трактов (ОППТ), синусоидально-гепатоцитарное число (СГЧ) - количество синусоидальных клеток на 1000 гепатоцитов. Кроме того, рассчитывали разработанный нами показатель, учитывающий данные микро- и макроморфометрии - общий объем гепатоцитов (ООГ), по формуле: ОПГ × ОП.

Для сравнения средних значений морфометрических показателей использовали t-критерий Стьюдента. Результаты биохимических показателей разбивали на градации, сравнивали с контрольными, используя метод углового пре-

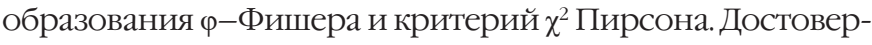
ными считали различия, если величина р была меныше 0,05.

Эксперимент выполнен согласно требованиям и положениям Европейской конвенции по защите позвоночных животных, используемых для экспериментальных и других научных целей (1986 г.). Исследование соответствует этичным принципам и нормам биомедицинских исследований с участием животных и одобрено комитетом по биоэтике Харьковской медицинской академии последипломного образования.

\section{Результаты}

Из 34 крыс экспериментальной группы погибла одна на 2-е сутки. Среди 33 выживших животных у одного на 21 -е и у двух на 35-е сутки отмечено нормальное содержание билирубина крови и отсутствие расширения ОЖП, то есть признаки полного восстановления желчеоттока (табл. 1). У 30 животных зафиксирована ЧООЖП (рис. 1).

Средний уровень общего билирубина у животных с ЧООЖП без гипербилирубинемии составил $(6,2 \pm 2,3)$ мкмоль/л ( $>$ > 0,05), у животных контрольной группы -

\begin{tabular}{|c|c|c|c|c|c|c|c|c|}
\hline \multirow[t]{2}{*}{ Таблица 1.} & \multicolumn{8}{|c|}{$\begin{array}{l}\text { Распределение животных с чООЖП по срокам эксперимента, уровню билирубинемии и наличию } \\
\text { расширения ОЖП }\end{array}$} \\
\hline \multirow{2}{*}{\multicolumn{2}{|c|}{ Наличие расширения ОЖП и гипербилирубинемии }} & \multicolumn{6}{|c|}{ Сроки эксперимента, сутки } & \multirow{2}{*}{ Итого } \\
\hline & & $3-n$ & 7-e & 14-e & $21-\mathrm{e}$ & $28-e$ & $35-e$ & \\
\hline \multicolumn{2}{|c|}{ Расширенный ОЖП с гипербилирубинемией } & 5 & 7 & 2 & - & 1 & 1 & 16 \\
\hline \multicolumn{2}{|c|}{ Расширенный ОЖП без гипербилирубинемии } & 1 & 3 & 1 & 4 & 2 & 3 & 14 \\
\hline \multicolumn{2}{|c|}{ Нерасширенный Ожп без гипербилирубинемии } & - & - & - & 1 & - & 2 & 3 \\
\hline \multicolumn{2}{|l|}{ Всего ... } & 6 & 10 & 3 & 5 & 3 & 6 & 33 \\
\hline
\end{tabular}


$(7,4 \pm 1,1)$ мкмоль/л, у животных с ЧООЖП и гипербилирубинемией - $(141 \pm 71,5)$ мкмоль/л ( $<<0,001$ в сравнении с показателями у животных с ЧООЖП без гипербилирубинемии).

Для выявления большей достоверности имеющихся различий животных с ЧООЖП без гипербилирубинемии объединили с учетом сроков эксперимента: 3 - 7-е, 14 21-е и 28-35-е сутки (табл. 2). В течение всего эксперимента диаметр ОЖП выше лигатуры был достоверно больше в сравнении с контрольным показателем $(\mathrm{p}<0,001)$.

На 3 - 7-е сутки при ЧООЖП без гипербилирубинемии МП и ОП не были увеличены, а микроскопическая картина незначительно отличалась от таковой у животных контрольной группы. Отмечены слабое полнокровие и лейкоцитоз сосудов портальных зон, увеличение числа синусоидальных клеток (ЧСК) и СГЧ (р < 0,001). Также наблюдали слабую острую воспалительную реакцию в виде полнокровия сосудов, их лейкоцитоза и скудной мононуклеарной инфильтрации отдельных портальных зон. Незначительно увеличивалось число желчных протоков (ЧжП) (p > 0,05) с их дилатацией. Отмечалась умеренная гиперплазия гепатоцитов (увеличение ПГ) и возрастание ЯЦО (различия ПГ и ЯЦО по сравнению с контрольными показателями недостоверны, p > 0,05). Между показателями ООГ достоверных различий также не выявлено.

На 14 - 21-е сутки достоверно увеличивались МП и ОП (см. табл. 2) на 19 и $11 \%$ соответственно ( $<<0,05)$. Гистологическая картина печени была достаточно однородной и характеризовалась слабым воспалительным ответом в виде полнокровия сосудов, умеренного лейкоцитоза, некоторым расширением портальной зоны за счет увеличенного ЧЖП, их дилатации и за счет слабой стромальной реакции с присутствием скудной круглоклеточной воспалительной инфильтрации. Однако статистической значимости (сл. табл. 2) увеличение ЧЖП не имело (р > 0,05). Несмотря на это, в 2 (40\%) из 5 наблюдений определялся слабый фиброз портальных зон без или с очень редкими тонкими порто-портальными септами, что со-

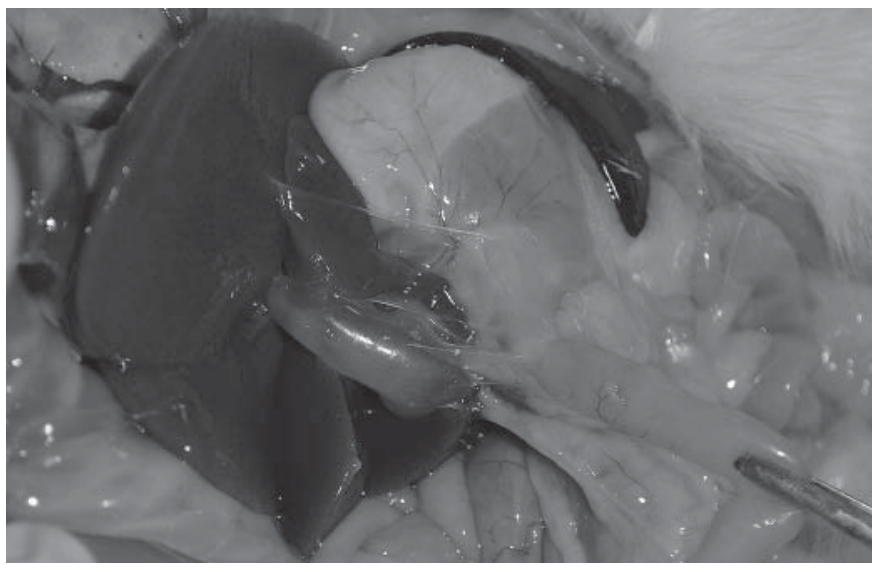

Puc. 1.

Расширенный ОЖП выше лигатуры у животного на 28-е сутки экспериментальной ЧООЖП без гипербилирубинемии.

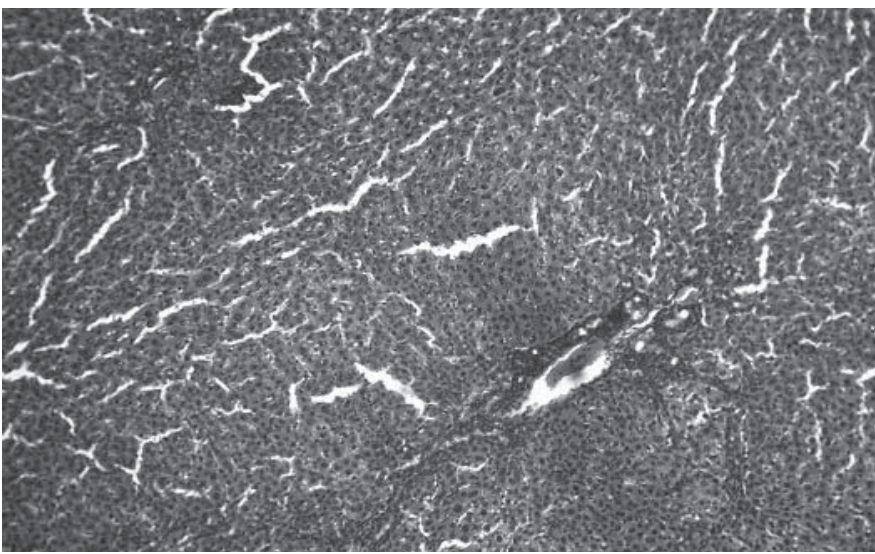

Puc. 2 .

Гистологическая картина печени крысы

на 28-е сутки ЧООЖП с нормальным содержанием билирубина крови. Определяется расширение портальных зон с пролиферачией желчных протоков и слабым фиброзом, формированием порто-портальных септ (II стадия); полнокровие, слабыйлейкоиитоз сосудов. Окраиивание гематоксилином и эозином.

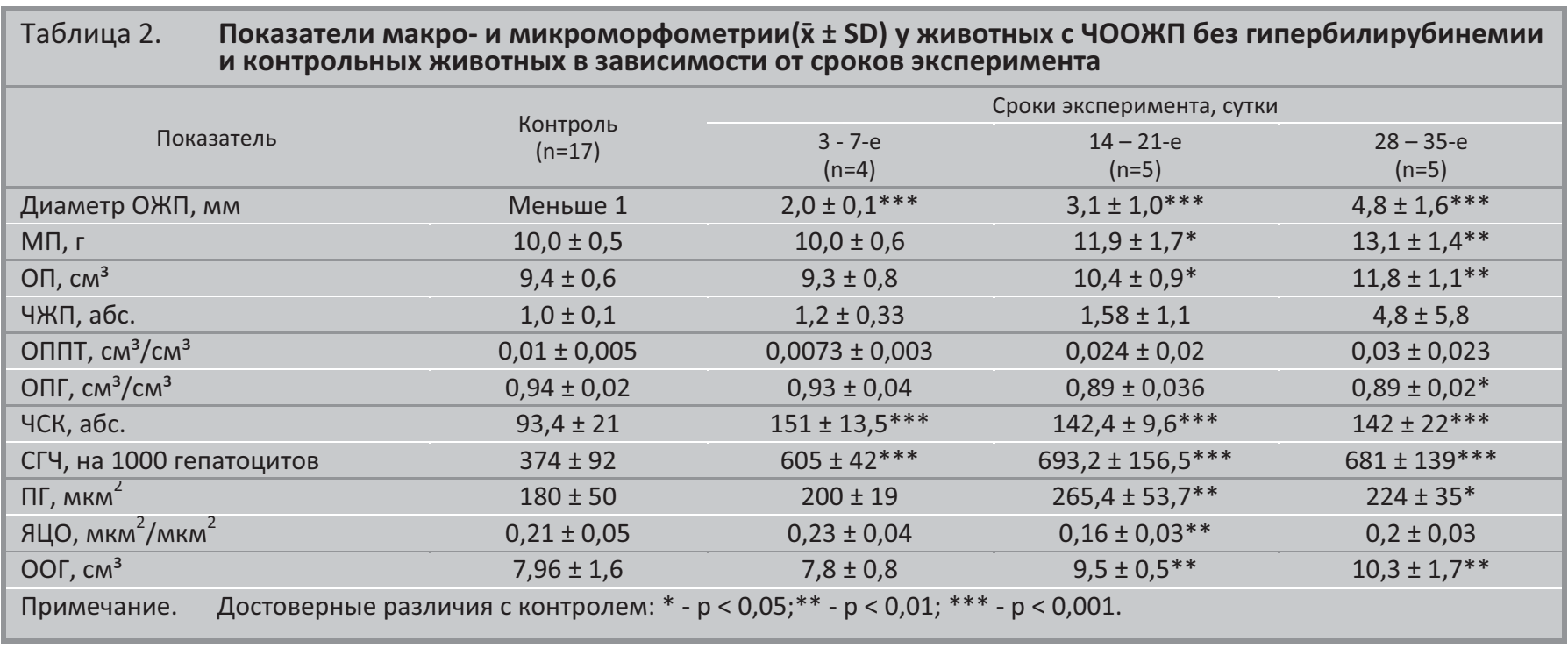




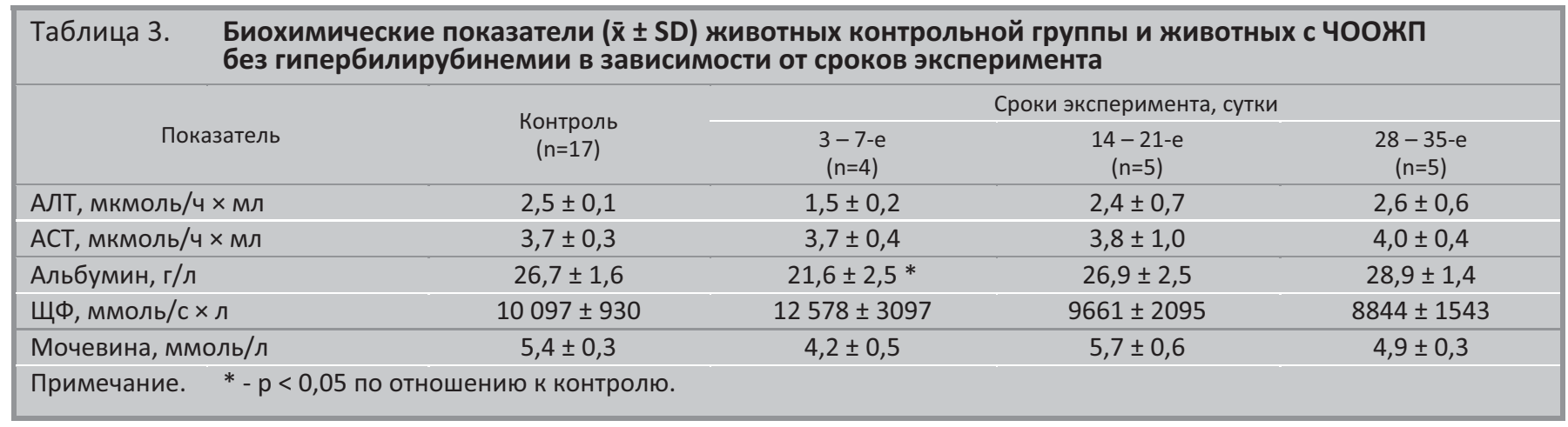

ответствовало I стадии. Достоверно увеличивалась ПГ (р $<0,01)$ при снижении ЯЦО ( $<<0,01)$. ООГ составил $(9,5$ $\pm 0,5) \mathrm{CM}^{3}$, что достоверно на $19,4 \%$ больше в сравнении с контрольным показателем - $(7,96 \pm 1,6)$ см $^{3}(\mathrm{p}<0,01)$.

В сравнении с животными контрольной группы на 28 - 35-е сутки при ЧООЖП без гипербилирубинемии МП и ОП были увеличены на 31 и 25,5\% соответственно (p < 0,01). Гистологическая картина печени существенно отличалась от нормы. Портальные зоны расширены с увеличением ЧЖП и ОППТ, однако за счет вариабельности показателей различия недостоверны ( $>$ > 0,05). У 4 из 5 животных отмечен фиброз (рис. 2) в портальных зонах с редкими порто-портальными септами, сопровождающими новообразованные желчные протоки, который соответствовал II стадии.

Определялись стромальная клеточная реакция со скудной мононуклеарной инфильтрацией, увеличением ЧСК и СГЧ ( $<<0,001)$, а также достоверное уменышение ОПГ $(\mathrm{p}<0,05)$. На 28 - 35-е сутки при ЧООЖП без гипербилирубинемии ООГ составил $(10,3 \pm 1,7)$ см $^{3}$, что на $29,4 \%$ больше в сравнении с контрольным показателем - $(7,96$ $\left.\pm 1,6 \mathrm{CM}^{3} ; \mathrm{p}<0,01\right)$.

При сопоставлении результатов биохимических анализов (табл.3) достоверные различия выявлены лишь на 3 - 7-е сутки в отношении содержания альбумина - при чООЖП без гипербилирубинемии этот показатель был на 19,1\% меньше контрольного (р < 0,05).

Показатели активности АЛТ, АСТ, ЩФ и содержания мочевины в исследуемые сроки достоверно не различались ( $\mathrm{p}>0,05)$.

\section{Обсуждение}

В клинической практике наличие обструктивного холестаза с клиникой обтурационной желтухи является показанием для проведения мероприятий, направленных на коррекцию имеющейся обструкции [1]. Целесообразность лечения билиарной обструкции без желтухи дискутабельна [3].

Поэтому данное исследование было направлено на выявление морфологических особенностей и функциональных изменений печени при экспериментальной ЧООЖП без гипербилирубинемии.

В ранее проведенном нами исследовании на том же экспериментальном материале установлено [8], что при
чООЖП с повышенным содержанием билирубина крови изменения печени сходны с таковыми при полной обструкции, но достоверно менее выражены, особенно с увеличением срока эксперимента. При ЧООЖП из 34 животных погибло одно, в то время как при полной обструкции - 70\% [8]. В других исследованиях, посвященных экспериментальной ЧООЖП, животные с нормальным уровнем билирубина крови отдельно не выделены, кроме того, продолжительность сроков этих исследований незначительна - до 12 - 14 сут [7, 11, 12]. В одном из исследований на мышах [11] приведено важное наблюдение - с нормализацией уровня билирубина отмечено обратное развитие фиброза.

Поэтому в данной работе мы сконцентрировались на морфологических изменениях печени и сдвигах биохимических показателей у животных с подтвержденной обструкцией, в том числе и длительной (до 35 сут), и нормальным уровнем билирубина крови.

Наличие обструкции у этих животных подтверждено расширением ОЖП в течение всего эксперимента, при этом с увеличением срока диаметр ОЖП также увеличивался, а максимальный диаметр ОЖП зафиксирован на 28 - 35-е сутки (см. мабл. 2).

При анализе полученных данных установлено, что ЧООЖП без гипербилирубинемии приводит к значимым морфологическим изменениям печени. Степень этих изменений зависит от срока эксперимента. Так, на 3 - 7-е сутки печень животных практически не отличается от нормальной, за исключением незначительной дилатации желчных протоков и реакции синусоидальных клеток - достоверного увеличения их количества ( $<<0,001)$. Единственным отклонением в изучаемых биохимических показателях является достоверное снижение содержания альбумина крови ( $<$ 0,05), что отражает нарушение белково-синтетической функции печени в эти сроки.

В последующем, на 14 - 21-е сутки, помимо сохраняющегося увеличения ЧСК и дилатации желчных протоков, присоединяется гипертрофия гепатоцитов, что сопровождается достоверным увеличением ПГ (p < 0,01) и снижением ЯЦО (p < 0,01). Следствием гипертрофии гепатоцитов является достоверное увеличения ООГ ( $<<0,01)$. Процессы гипертрофии гепатоцитов и увеличения ООГ отражают состояние функционального напряжения ор- 
гана, хотя это и никак не отразилось на биохимических показателях - они не отличались от контрольных. Последнее свидетельствует о полной компенсации функционирования печени.

Однако важным является то, что, несмотря на минимальные морфологические проявления холестаза и отсутствие биохимических нарушений, на 14 - 21-е сутки в 2 из 4 наблюдений определялись признаки начального фиброза печени I степени [10].

На 28 - 35-е сутки морфологические изменения печени нарастают. За счет дилатации и пролиферации желчных протоков их число увеличивается, хотя из-за вариабельности показателя достоверности это увеличение не имеет ( $p>0,05)$. Достоверно снижается ОПГ ( $<<0,05)$, что свидетельствует о замещении гепатоцитов, хотя и за счет сохраняющейся гипертрофии гепатоцитов общий их объем превышает контрольный показатель $(\mathrm{p}<0,05)$. Нарастает и процесс фиброзирования, в эти сроки он отмечен у 4 из 5 животных с изменениями, характерными для II степени [10]. Все это сопровождается достоверным увеличением как массы, так и объема печени.

Отсутствие достоверных различий в биохимических показателях на 14 - 35-е сутки свидетельствует о полной функциональной компенсации печени.

Обобщая полученные данные, можно сделать следующие заключения:

чООЖП с нормальным содержанием билирубина крови приводит к морфологическим изменениям печени, степень которых зависит от длительности эксперимента; максимальные изменения печени зафиксированы на 28 - 35-е сутки: увеличение органа, уменьшение доли гепатоцитов, их гипертрофия и как следствие увеличение ООГ, ЧСК, развитие фиброза печени II степени; динамика биохимических показателей в целом свидетельствует о функциональной компенсации печени, однако на 3 -7-е сутки происходит снижение ее белково-синтетической функции.

\section{Выводы}

Несмотря на полную функциональную компенсацию, чООЖП без гипербилирубинемии приводит к значимым морфологическим изменениям печени, в том числе к развитию и прогрессированию фиброза.

\section{Подтверждение}

Финансирование. За счет средств авторов.

Информация об участии авторов. Мамонтов И. Н. - концепция и дизайн исследования, проведение эксперимента, анализ данных, написание текста; Тамм Т. И. концепция и дизайн исследования; Ивахно И. В. - выполнение патогистологического исследования, анализ данных, написание текста; Панасенко В. А. - проведение эксперимента, сбор и обработка материала; Падалко В. И. проведение эксперимента, сбор материала; Зульфугаров И. И. - сбор материала.
Конфликт интересов. Авторы, которые приняли участие в этом исследовании, заявили, что у них нет конфликта интересов в отношении этой рукописи.

Согласие на публикацию. Все авторы прочитали и одобрили окончательный вариант рукописи. Все авторы дали согласие на публикацию этой рукописи.

\section{References}

1. Modha K. Clinical approach to patients with obstructive jaundice. Tech Vasc Interv Radiol. 2015;18(4):197-200. doi: 10.1053/j.tvir.2015.07.002.

2. Veligotsky NN, Arutyunov SE, Lazutkina EA. Gallstone disease complicated by cholestasis. Ukrainian Journal of Surgery. 2018;1(36):21-3. doi: 10.22141/1997-2938.1.36.2018.133001. [In Russian].

3. Testoni PA. No treatment for asymptomatic common bile ducts stones? Endosc Int Open. 2017;5(11):E1151-E1152. doi: 10.1055/s-0043107778 .

4. Rodriguez-Garay EA. Cholestasis: human disease and experimental animal models. Ann Hepatol. 2003;2(4):150-8. PMID: 15115953.

5. Tag CG, Weiskirchen S, Hittatiya K, Tacke F, Tolba RH, Weiskirchen R. Induction of experimental obstructive cholestasis in mice. Lab Anim. 2015;49(1 Suppl):70-80. doi: 10.1177/0023677214567748.

6. Tag CG, Sauer-Lehnen S, Weiskirchen S, Borkham-Kamphorst E, Tolba RH, Tacke F, et al. Bile Duct Ligation in Mice: Induction of Inflammatory Liver Injury and Fibrosis by Obstructive Cholestasis. J Vis Exp. 2015;(96):5243. doi: 10.3791/52438.

7. Heinrich S, Georgiev P, Weber A, Vergopoulos A, Graf R, Clavien PA. Partial bile duct ligation in mice: a novel model of acute cholestasis. Surgery. 2011;149(3):445-51. doi: 10.1016/j.surg.2010.07.046.

8. Mamontov IN, Tamm TI, Ivakhno IV, Panasenko VA, Padalko VI. Morphological changes of the liver in experimental partial obstruction of the common bile duct. Klinichna khirurhiia. 2017;(12):59-63. doi: 10.26779/2522-1396.2017.12.59.

9. Sekas G. A technique for creating partial obstruction of the common bile duct in the rat. Lab Anim. 1990;24(3):284-7. doi: 10.1258/002367790780866236.

10. Ishak K, Baptista A, Bianchi L. Histological grading and staging of chronic hepatitis. J Hepatol. 1995;22(6):696-9. doi: 10.1016/01688278(95)80226-6.

11. Hiroaki Aoki, Masayo Aoki, Jing Yang, Eriko Katsuta, Partha Mukhopadhyay, Rajesh Ramanathan, et all. Murine model of long term obstructive jaundice. J Surg Res. 2016;206(1):118-25. doi:10.1016/j.jss.2016.07.020.

12. Rodriguez-Garay EA, Rodríguez GP, Pisani G, Taborda M, Viglianco RA. Reversible cholestasis induced by experimental partial obstruction of the bile duct Biochemical, morphometric and hepatic transport kinetic studies. Pathophysiology. 2004;11(1):7-15. doi:10.1016/j.pathophys.2003.09.002

Надійшла17.06.19 